\title{
Cough Peak Flow of Independent Elderly People
}

\author{
Yoshihiro Yamashina ${ }^{1}$, Kazuyuki Tabira ${ }^{2}$, Hiroki Aoyama1, Tomoko Hirayama1, \\ Hiroto Honda1, Yosuke Yamato' ${ }^{1}$, Emiko Morita1, Nami Sakagami1, Yumi Fukuyama1, \\ Sho Kumabe', Shigeru Terada ${ }^{1}$, Masahiro Goto ${ }^{1}$
}

${ }^{1}$ Department of Physical Therapy, Aino University, Osaka, Japan

${ }^{2}$ Department of Physical Therapy, Kio University, Nara, Japan

Email: *y-yamashina@pt-u.aino.ac.jp

How to cite this paper: Yamashina, Y., Tabira, K., Aoyama, H., Hirayama, T., Honda, H., Yamato, Y., Morita, E., Sakagami, N., Fukuyama, Y., Kumabe, S., Terada, S., \& Goto, M. (2020). Cough Peak Flow of Independent Elderly People. Advances in Physical Education, 10, 347-353.

https://doi.org/10.4236/ape.2020.104028

Received: August 24, 2020

Accepted: October 17, 2020

Published: October 20, 2020

Copyright () 2020 by author(s) and Scientific Research Publishing Inc. This work is licensed under the Creative Commons Attribution International License (CC BY 4.0).

http://creativecommons.org/licenses/by/4.0/

\begin{abstract}
Introduction: This study aimed to investigate the cough strength and respiratory function as well as the factors affecting the cough strength of independent elderly people. Methods and Results: A total of 36 elderly people participated in this experiment, and two subjects with hypertension were excluded. All subjects were evaluated for vital capacity (VC), cough peak flow $(\mathrm{CPF})$, and respiratory muscle strength by determination of the maximum inspiratory and expiratory pressure (PImax and PEmax, respectively) in a sitting position. Each measurement consisted of three trials, and the maximum values were adopted for the analysis. The average value of CPF was $291.5 \pm$ $100.5 \mathrm{~L} / \mathrm{min}$. Moreover, 17 out of the 34 subjects had CPF $<270 \mathrm{~L} / \mathrm{min}$. A significant positive correlation was found between $\mathrm{CPF}$ and VC $(\mathrm{r}=0.53, P<$ 0.05). A significant negative correlation was found between age and $\mathrm{CPF}(\mathrm{r}=$ $-0.64, P<0.05)$ and VC $(\mathrm{r}=-0.40, P<0.05)$. No significant correlation was found between respiratory muscle strength (inspiratory muscle strength and expiratory muscle strength) and CPF. Conclusion: Elderly people who independently perform their activities of daily living do not always have high coughing ability and may have reduced VC associated with reduced coughing ability.
\end{abstract}

\section{Keywords}

Cough Peak Flow, Independent Elderly, Vital Capacity, Respiratory Muscle Strength

\section{Introduction}

In recent years, pneumonia has accounted for a large percentage of deaths in the elderly (Zalacain \& Torres, 2004; Higuchi et al., 2007). One reason for this is the 
decline in the host defense function. Coughing plays an important role in the host defense function through airway clearance by sputum expectoration. Forceful and effective coughing successfully removes invading organisms with respiratory tract secretions. Therefore, decreased cough capacity augments the risk of developing pulmonary complications (Higuchi et al., 2007; Smith Hammond et al., 2001; Kimura et al., 2013; Mahajan et al., 1994). Prevention of pneumonia is important for maintaining health in independently living elderly people (Takeda et al., 2004; Graton \& Grossman, 1993).

Cough peak flow $(\mathrm{CPF})$ is known to adequately reflect cough capacity. Bach et al. have reported that a CPF of $\leq 270 \mathrm{~L} / \mathrm{min}$ during an infection and of $\leq 160$ $\mathrm{L} / \mathrm{min}$ under normal conditions indicates that sputum expectoration is difficult for patients with neuromuscular disease (Bach \& Saporito, 1996). Yamakawa et al. also reported that the levels of CPF for judging self-clearing ability and the necessity of suction were $240 \mathrm{~L} / \mathrm{min}$ and $100 \mathrm{~L} / \mathrm{min}$ for middle-aged and elderly patients in a hospital, respectively (Yamakawa et al., 2010). Furthermore, CPF is correlated with vital capacity (VC) and respiratory muscle strength (maximal expiratory mouth pressure: PEmax; maximal inspiratory mouth pressure: PImax) represented by maximal inspiratory mouth pressure (Kang et al., 2006; Park et al., 2010). Therefore, CPF is considered to be a simple and reliable indicator for cough capacity and has been practically used in clinical settings for evaluating the cough capacity. Moreover, the routine activities of daily living (ADL) performed by the elderly can have an influence on their CPF (Yamashita \& Ito, 2013). In addition, it is reported that $26 \%$ of community-dwelling elderly decreased CPF (Kaneko et al., 2019). There are some reports about CPF among those with disease; however, there are few reports regarding independent elderly people. Therefore, we investigated the cough strength and respiratory function as well as the factors affecting the cough strength of independent elderly people.

\section{Patients, Material and Methods}

\subsection{Subjects}

We recruited elderly people aged $>60$ years who independently performed their ADL. A total of 36 elderly people participated in this experiment [male: 21 ; female: 15 ; age: $70.1 \pm 7.3$ years; weight: $59.4 \pm 6.8 \mathrm{~kg}$; height: $157.4 \pm 7.1 \mathrm{~cm}$; body mass index (BMI): $23.7 \pm 2.2 \mathrm{~kg} / \mathrm{m}^{2}$ ]. No subjects had a history of respiratory or cardiovascular disease, hypertension [resting systolic blood pressure (BP) $\geq 140$ $\mathrm{mmHg}$ and/or diastolic $\mathrm{BP} \geq 90 \mathrm{mmHg}$ ], diabetes, or obesity $\left(\mathrm{BMI} \geq 30 \mathrm{~kg} / \mathrm{m}^{2}\right)$, or a habit of smoking. Before participation, written consent was obtained from all subjects after a thorough written and oral explanation of the purpose, methods, and risks of this study (Figure 1). The research ethics committee of Aino University approved this study protocol.

\subsection{Anthropometric Measurements and Confirmation of Activities of Daily Living}

We measured the weight, height, and BMI and confirmed ADL using Barthel 
Index before the start of the experiment.

\subsection{Measurement of Vital Capacity, Cough Peak Flow and Respiratory Muscle Strength}

All the subjects who wore a nose clip were evaluated for VC and CPF using an electronic spirometer (AS-307, MINATO) with a mouthpiece in the sitting position. The respiratory muscle strength was evaluated by determination of maximum inspiratory and expiratory pressure (PImax and PEmax, respectively), considered as the surrogate indices of inspiratory and expiratory muscle strength, which were evaluated using a sthenometer attached to a spirometer (AAM337, Minato, Osaka, Japan) based on the Black and Hyatt method (Black \& Hyatt, 1969). For the seated measurement, the subjects sat on a backless chair and placed both of their hands on their thighs. Each measurement consisted of three trials, and the maximum values were adopted for the analysis.

The measurement of VC and CPF was performed in the usual manner as mentioned elsewhere. In brief, after some practice, VC was determined while the subjects held the mouthpiece connected to the spirometer in their mouth and breathed slowly from the maximum inspiratory level to the maximum expiratory level. In regard to $\mathrm{CPF}$, all subjects who held the mouthpiece were instructed to inhale as much as possible and then spontaneously cough with maximum effort (Figure 2).

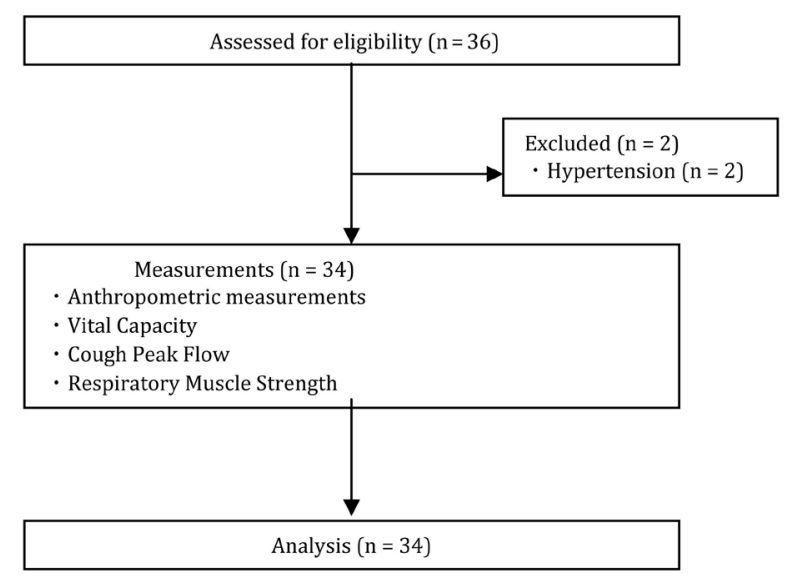

Figure 1. Flow diagram of study subjects.

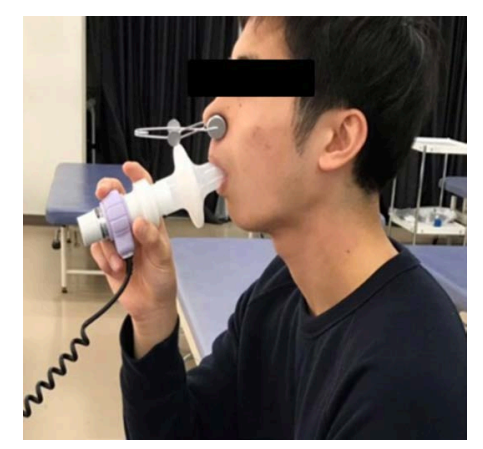

Figure 2. Measurements of vital capacity and cough peak flow. 


\subsection{Statistical Analysis}

All statistical analyses were performed using StatView (SAS Institute Inc., Cary, $\mathrm{NC}$, USA), and all the values were shown as mean \pm standard deviation. We conducted a Pearson's correlation analysis of the relationship between CPF and age, VC, and respiratory muscle strength. $P<0.05$ was considered statistically significant.

\section{Results}

We excluded two subjects with hypertension. We therefore analyzed the data of 34 people (male: 19; female: 15; age: $69.5 \pm 7.0$ years; weight: $59.9 \pm 6.7 \mathrm{~kg}$; height: $158.0 \pm 6.7 \mathrm{~cm}$; BMI: $23.8 \pm 2.2 \mathrm{~kg} / \mathrm{m}^{2}$ ). All subjects' Barthel Index scores were 100 points. The average value of CPF was $291.5 \pm 100.5 \mathrm{~L} / \mathrm{min}$. Moreover, 17 out of the 34 subjects had $\mathrm{CPF}<270 \mathrm{~L} / \mathrm{min}$. A significant positive correlation was found between $\mathrm{CPF}$ and $\mathrm{VC}(\mathrm{r}=0.53)$, whereas a significant negative correlation was found between age and CPF $(r=-0.64)$ and VC $(r=-0.40)$. Furthermore, no significant correlation was found between respiratory muscle strength (inspiratory muscle strength and expiratory muscle strength) and CPF $(\mathrm{r}=-0.06$ and $\mathrm{r}=0.08$, respectively) (Table 1 , Table 2$)$.

\section{Discussion}

In this study, the average CPF measured was above the limit of $270 \mathrm{~L} / \mathrm{min}$ required for effective coughing (Bach \& Saporito, 1996), although some of the values were below this point, indicating that some elderly people who are independent in their daily lives may have expectorant dysfunction when a respiratory

Table 1. The respiratory functions of the subjects.

\begin{tabular}{cc}
\hline Number & 34 \\
VC $(\mathrm{L})$ & $2.8 \pm 0.5$ \\
$\mathrm{CPF}(\mathrm{L} / \mathrm{min})$ & $291.5 \pm 100.5$ \\
PImax $\left(\mathrm{cm} \mathrm{H}_{2} \mathrm{O}\right)$ & $50.5 \pm 11.1$ \\
PEmax $\left(\mathrm{cm} \mathrm{H}_{2} \mathrm{O}\right)$ & $56.7 \pm 13.5$
\end{tabular}

Values are means \pm SD. Abbreviations: VC, vital capacity; CPF, cough peak flow; PImax, maximum inspiratory pressure; $\mathrm{PEmax}$, maximum expiratory pressure.

Table 2. Relationships between CPF and parameters.

\begin{tabular}{ccc}
\hline & Correlation coefficient & $p$ value \\
\hline Age & -0.64 & $p<0.05$ \\
VC & 0.53 & $p<0.05$ \\
PImax & -0.06 & $p>0.05$ \\
PEmax & 0.08 & $p>0.05$ \\
\hline
\end{tabular}

Abbreviations: VC, vital capacity; CPF, cough peak flow; PImax, maximum inspiratory pressure; PEmax, maximum expiratory pressure. 
tract infection occurs. The mechanism of coughing consists of the following three phases (Shannon et al., 1997): a large inhalation (inspiratory phase); a forced exhalation against a closed glottis (compressive phase); and an intense airflow from the lungs following opening of the glottis, usually accompanied by a peculiar sound (expulsive phase). Therefore, coughing is an action that requires both an inhalation and an expiration function. Previous studies have reported that with age, thoracic flexibility and VC decrease. Although we did not measure thorax flexibility in this study, we found a moderate negative correlation between age and VC and $\mathrm{CPF}$ and a moderate positive correlation between VC and CPF. Therefore, it is considered that aging decreased the flexibility of the thorax, making it difficult to perform deep inspiration in the first phase during voluntary coughing and reduced coughing power. No significant correlation was found between respiratory muscle strength (inspiratory muscle strength and expiratory muscle strength) and coughing in this study. As described previously, coughing may require inspiratory and expiratory functions, but the subjects were elderly people who independently perform ADL and did not recognize the decrease in their respiratory muscle strength. These results suggest that the $\mathrm{CPF}$ decline in the elderly who independently perform ADL may have caused their decreased VC.

On the basis of the results of this study, we found that even if a person can independently perform ADL, their coughing ability is not necessarily high. Therefore, an exercise program that not only improves limb muscle strength and ADL but also maintains and improves respiratory function, including coughing ability, is necessary to consider for health promotion.

This study has some research limitations. It has been reported that VC is reduced in an individual with a circular posture (Leech et al., 1990; Culham et al., 1994). In this study, the presence or absence of a spine malformation was examined by visual inspection, and no patient had apparent problems on their spine. Nevertheless, because the spine was not strictly examined with the use of a device, such as the SPINAL MOUSE (Index Ltd.), the possibility of the presence of a slight deformation in the patients cannot be denied. In addition, blood tests were not examined for checking the patients' nutritional status. In actually, we did not confirm whether older people with low CPF could not expectorate. In the future, it is necessary to measure the CPF of elderly people who cannot actually expectorate and compare it with the data obtained in this study. Therefore, it is necessary to consider these limitations in the future.

\section{Acknowledgements}

We are grateful to members of Aino University for their important contributions to this experiment. This research was supported by a grant from Aino University.

\section{Conflicts of Interest}

The authors declare that they have no competing interests. 


\section{References}

Bach, J. R., \& Saporito, L. R. (1996). Criteria for Extubation and Tracheostomy Tube Removal for Patients with Ventilatory Failure: A Different Approach to Weaning. Chest, 110, 1566-1571. https://doi.org/10.1378/chest.110.6.1566

Black, L. F., \& Hyatt, R. E. (1969). Maximal Respiratory Pressures: Normal Values and Relationship to Age and Sex. The American Review of Respiratory Disease, 99, 696-702.

Culham, E. G., Jimenez, H. A., \& King, C. E. (1994). Thoracic Kyphosis, Rib Mobility, and Lung Volumes in Normal Women and Women with Osteoporosis. Spine, 19, 1250-1255. https://doi.org/10.1097/00007632-199405310-00010

Graton, J. T., \& Grossman, R. F. (1993). Community-Acquired Pneumonia in the Elderly Patient. Clinical Features Epidemiology and Treatment. Clinics in Chest Medicine, 14, 537-553.

Higuchi, T., Ota, K., Tanabe, Y., Suzuki, E., \& Gejyo, F. (2007). Severity Classification and Prognosis in Hospitalized Elderly Patients with Community-Acquired Pneumonia. Nippon Ronen Igakkai Zasshi, 44, 483-489. https://doi.org/10.3143/geriatrics.44.483

Kaneko, H., Suzuki, A., \& Horie, J. (2019). Relationship of Cough Strength to Respiratory Function, Physical Performance, and Physical Activity in Older Adults. Respiratory Care, 64, 828-834. https://doi.org/10.4187/respcare.06490

Kang, S. W., Kang, Y. S., Sohn, H. S., Park, J. H., \& Moon, J. H. (2006). Respiratory Muscle Strength and Cough Capacity in Patients with Duchenne Muscular Dystrophy. Yonsei Medical Journal, 47, 184-190. https://doi.org/10.3349/ymj.2006.47.2.184

Kimura, Y., Takahashi, M., Wada, F., \& Hachisuka, K. (2013). Differences in the Peak Cough Flow among Stroke Patients with and without Dysphagia. Journal of UOEH, 35, 9-16. https://doi.org/10.7888/juoeh.35.9

Leech, J. A., Dulberg, C., Kellie, S., Pattee, L., \& Gay, J. (1990). Relationship of Lung Function to Severity of Osteoporosis in Women. The American Review of Respiratory Disease, 141, 68-71. https://doi.org/10.1164/ajrccm/141.1.68

Mahajan, R. P., Sing, R. P., Murty, G. E., \& Aitkenhead, A. R. (1994). Relationship between Expired Lung Volume, Peak Flow Rate and Peak Velocity Time during a Voluntary Cough Manoeuvre. British Journal of Anaesthesia, 72, 298-301. https://doi.org/10.1093/bja/72.3.298

Park, J. H., Kang, S. W., Lee, S. C., Choi, W. A., \& Kim, D. H. (2010). How Respiratory Muscle Strength Correlates with Cough Capacity in Patients with Respiratory Muscle Weakness. Yonsei Medical Journal, 51, 392-397. https://doi.org/10.3349/ymj.2010.51.3.392

Shannon, R., Bolser, D. C., \& Lindsey, B. G. (1997). Neural Control of Coughing and Sneezing. In Neural Control of the Respiratory Muscles (pp. 213-222). Tokyo: CRC Press. https://doi.org/10.1201/9780429277740-18

Smith Hammond, C. A., Goldstein, L. B., Zajac, D. J., Gray, L., Davenport, P. W., \& Bolser, D. C. (2001). Assessment of Aspiration Risk in Stroke Patients with Quantification of Voluntary Cough. Neurology, 56, 502-506. https://doi.org/10.1212/WNL.56.4.502

Takeda, M., Sato, T., Senpuku, H., \& Hanada, N. (2004). Comparison of Oral Microflora between Independent and Dependent Elderly. Journal of Dental Health, 54, 178-188.

Yamakawa, R., Yokoyama, H., Watanabe, Y., Yokoyama, Y., Takeichi, N., Ihizaka, S., Okada, K., \& Sasa, M. (2010). The Level of Cough Peak Flow for Judging Ability of Clear Airway Secretion in Middle-Old Age Subjects. Jinkoukokyu, 27, 82-88.

Yamashita, K., \& Ito, K. (2013). Relationship between Voluntary Cough Intensity and 
ADL Performance of Stroke Patients. Rigakuryoho Kagaku, 28, 105-108. https://doi.org/10.1589/rika.28.105

Zalacain, R., \& Torres, A. (2004). Pneumonia in the Elderly. Clinical Pulmonary Medicine, 11, 210-218. https://doi.org/10.1097/01.cpm.0000132888.49928.86 